\title{
Immunization of rats and sheep against granulosa cell-inhibitory factor from bovine follicular fluid increases the number of large follicles in rats and the ovulation rate in sheep
}

\author{
A. C. Hynes ${ }^{1}$, M. T. Kane ${ }^{1}$ and J. M. Sreenan ${ }^{2 *}$ \\ ${ }^{1}$ Department of Physiology, National University of Ireland, Galway, Ireland; and ${ }^{2}$ Agriculture and Food Development Authority, Belclare, \\ Tuam, County Galway, Ireland
}

\begin{abstract}
Granulosa cell-inhibitory factor (GCIF), a low molecular weight factor from bovine follicular fluid, inhibits the proliferation of bovine granulosa cells in vitro and the growth of large follicles in rats in vivo. In this study the effects of (1) immunization of rats against GCIF on follicular growth and (2) immunization of sheep against GCIF on ovulation rate were studied. The ability of antiserum from sheep immunized against GCIF to reduce the inhibitory effect of GCIF on bovine granulosa cell proliferation in culture was also examined. Immunization of rats against GCIF increased the number of large follicles $(P<0.001)$ but decreased the number of small follicles $(P<0.05)$ per ovary. Ovarian mass $(P<0.05)$ and uterine wet $(P<0.05)$ and dry $(P<0.01)$ masses were increased in immunized rats. Immunization of sheep against GCIF, followed by boosting over two breeding seasons, increased ovulation rate $(P<0.01)$. Addition of antiserum from sheep immunized against GCIF reduced or abolished the inhibitory effect of GCIF on granulosa cell proliferation $(P<0.01)$. These data provide further evidence that GCIF has an important role in controlling follicle growth and ovulation in vivo.
\end{abstract}

\section{Introduction}

Knowledge of the control of ovarian follicle growth and ovulation is crucial to devising better methods for the control of both human and farm animal reproduction. For many years, it was thought that ovulation was strictly controlled by gonadotrophins and the ovarian steroids, and by interactions between these compounds. However, in spite of the fact that in monovular species, such as cattle and humans, many follicles develop as a cohort and are subjected to the same endogenous gonadotrophic environment and are, in theory, all capable of ovulating, normally only one follicle from the cohort is ovulated and the remainder undergo atresia (Spicer and Echternkamp, 1986). McNatty and Sawers (1975) showed that removal of large follicles from the ovary by cauterization was associated with a compensatory increase in the mitotic index of granulosa cells in the remaining follicles and they postulated that the cauterization of large follicles removed an endogenous inhibitor of granulosa cell mitosis present in the follicular fluid of such follicles. This hypothesis was supported by the finding of Cahill et al. (1984) that administration of steroidfree ovine follicular fluid to PMSG-treated hypophysectomized sheep significantly inhibited the growth of follicles

*Correspondence.

Revised manuscript received 12 November 1998. to $>2-4 \mathrm{~mm}$ in diameter (for a review of more recent work, see Ginther et al., 1996).

The partial purification of a granulosa cell inhibitory factor (GCIF) of low molecular mass $\left(<5000 M_{\mathrm{r}}\right)$ from bovine follicular fluid that inhibited granulosa cell proliferation in vitro has been reported (Hynes et al., 1996a). Injection of GCIF into female rats decreased the number of large follicles, increased the number of small follicles, and decreased ovarian and uterine mass. In vitro, GCIF markedly reduced the stimulatory effects of $\mathrm{FSH}$, androstenedione, epidermal growth factor (EGF) and insulin-like growth factor I (IGF-I) on granulosa cell proliferation, indicating that it may play a significant role in modulating the effects of systemic hormones and intraovarian growth factors on granulosa cells and on the growth of follicles. GCIF also decreased the stimulatory effect of IGF-I on the aromatase activity of granulosa cells in vitro. Two factors with similar properties to GCIF have been reported by other workers. Kigawa et al. (1986) partially purified a factor with an estimated $M_{\mathrm{r}}$ of $1-3 \mathrm{kDa}$ from pig follicular fluid that inhibited oestradiol and progesterone secretion both by rat granulosa cells in vitro and by the ovaries of hypophysectomized diethylstilboestrol-treated immature rats in vivo. Another factor with similar activity to GCIF was described by Chakravorty et al. (1991); this factor was isolated from $a<10 \mathrm{kDa}$ fraction of rat follicular fluid and was named granulosa cell mitostatic protein (GCMP). 
In the present study, female rats and sheep were immunized against GCIF, and reproductive function was monitored after booster injections. The effect of antiserum collected from sheep immunized against GCIF on the inhibitory effect of GCIF on granulosa cell proliferation was also examined.

\section{Materials and Methods}

\section{Conjugation procedure}

GCIF was purified and tested for granulosa cell inhibitory activity as described by Hynes et al. (1996a). Briefly, steroids were removed from bovine follicular fluid with dextranactivated charcoal (Sigma, Poole) and the follicular fluid was separated into $<10 \mathrm{kDa}$ and $>10 \mathrm{kDa}$ fractions by passing it through a hollow fibre unit (Amicon Ltd, Stonehouse). The $<10 \mathrm{kDa}$ fraction was freeze-dried and fractionated on a Sephadex G-25 superfine column using 5\% (v/v) formic acid as the eluent. The peak corresponding to the granulosa cell inhibitory factor (GCIF) as described by Hynes et al. (1996a) was conjugated to human serum albumin (HSA, Sigma) using the method of Goodfriend et al. (1964) with some modifications (Briand et al., 1985; Staros et al., 1986). In this reaction, 1-ethyl-3-(3-dimethylaminopropyl) carbodiimide hydrochloride (EDC) catalyses the formation of amide bonds between carboxylic acids and amines and the reaction is enhanced by the presence of $\mathrm{N}$-hydroxysulfosuccinimide (NHS).

Human serum albumin $(8.7 \mathrm{mg})$ was added to $4 \mathrm{mg}$ (peptide equivalent) of GCIF and $1.1 \mathrm{mg}$ NHS (Sigma) to produce $10 \mathrm{mg}$ of the GCIF-HSA conjugate. Assuming that the molecular weight of GCIF lies in the range 1-5 kDa (Hynes et al., 1996a), this gives a ratio of moles of GCIF to moles of carrier of from 32:1 to 6.4:1 and a ratio of EDC to GCIF of from 31:1 to 155:1. The amount of peptide equivalent material in the GCIF fraction was determined by absorbance measurements at 260 and $280 \mathrm{~nm}$ (Johnstone and Thorpe, 1982). Coupling was initiated by adding GCIF, HSA and NHS to a final volume of $2.3 \mathrm{ml}$ of $50 \mathrm{mmol} 2$-( $N$-morpholino)ethanesulfonic acid $\mathrm{l}^{-1}$ (MES buffer, Sigma) containing $23.93 \mathrm{mg}$ EDC (125 mmol). The $\mathrm{pH}$ of the reaction mixture was monitored closely for $2-3 \mathrm{~h}$ after the initiation of coupling and maintained between $5.5-6.0$ by the addition of $0.1 \mathrm{mmol} \mathrm{NaOH} \mathrm{l^{-1 }}$ or $0.1 \mathrm{mmol} \mathrm{HCl}$ $\mathrm{I}^{-1}$ as required. The reaction was allowed to continue overnight at room temperature with continuous stirring. The conjugate solution was then dialysed against four changes of deionised water over $24 \mathrm{~h}$ and lyophilized thoroughly.

GnRH was conjugated to HSA using the same method and concentrations as described for GCIF. GnRH was used as a control to check on the conjugation and immunization procedures. When HSA alone was used for immunization, it was taken through the same conjugation procedure.

\section{Immunization of rats}

Virgin Sprague-Dawley rats (Harlan Olac, Shaws Farm, Blackthorn, Oxfordshire), aged 8-10 weeks at the time of primary immunization were used. The rats were maintained in groups of four per cage. Vaginal smears were taken daily and stained with $0.1 \%(\mathrm{v} / \mathrm{v})$ Giemsa stain for $15 \mathrm{~min}$ to determine the occurrence of normal oestrous cycles.

Rats in which at least two consecutive 4 or 5 day oestrous cycles had been recorded were used. Fifteen rats were allocated in equal numbers randomly to one treatment and two control groups. The treatment group was immunized with $50 \mu \mathrm{g}$ GCIF-HSA conjugate (dissolved in $500 \mu \mathrm{l}$ sodium chloride solution and emulsified in an equal volume of Freund's complete adjuvant, FCA) per animal. The emulsion was injected subcutaneously at five sites in each animal. Booster injections were given 6 weeks after the primary immunization at a rate of $20 \mu \mathrm{g}$ of GCIF-HSA conjugate in $500 \mu \mathrm{l}$ sodium chloride solution emulsified in an equal volume of non-ulcerative Freund's adjuvant (NUFA) per animal. One control group consisted of rats immunized and boosted against HSA alone using the same procedure and concentrations as for GCIF. A second control group consisted of rats that were untreated.

\section{Measurement of number of follicles and ovarian, uterine, liver and kidney mass in rats}

Rats were killed on day 14 after the booster injection using diethyl ether. The liver, kidneys, uterus and ovaries were excised, all surplus surrounding tissue was dissected away from the organs and each organ was then weighed. Liver and kidney masses were recorded to determine possible nonspecific effects of immunization against GCIF. Uterine and ovarian masses were recorded as a measure of ovarian function. The uteri were then lyophilized and their dry masses were determined to measure whether changes in organ mass were due to fluid accumulation within the uterus or to tissue growth or atrophy. After weighing, the ovaries were examined under a dissection microscope and follicles present on the ovarian surface were counted and classified as large or small follicles. Vesicular follicles protruding from the surface of the ovary were classified as large follicles, while vesicular follicles not protruding from the ovarian surface were classified as small follicles.

\section{Immunization of sheep}

Mature ewes of Cambridge and Belclare ancestry were immunized against either HSA alone (control group, $n=8$ ), GCIF-HSA-peak 4 conjugate $(n=7)$ or GnRH-HSA-peak 4 conjugate $(n=8)$. The effects of immunization against $\mathrm{GnRH}$ were examined because $\mathrm{GnRH}$ is a peptide in a similar molecular weight range $(<5 \mathrm{kDa})$ to GCIF (Hynes et al., 1996a). The same immunization protocol was followed for each immunization group. Conjugate or HSA $(3 \mathrm{mg})$ was dissolved in $2 \mathrm{ml}$ sodium chloride solution $(0.9 \%, \mathrm{v} / \mathrm{v})$ and emulsified in an equal volume of FCA. Ewes were immunized by subcutaneous injection of the emulsified conjugate at four sites in the axillary region.

Booster injections of conjugate or HSA $(1 \mathrm{mg})$ were dissolved in $2 \mathrm{ml}$ sodium chloride solution as for primary 

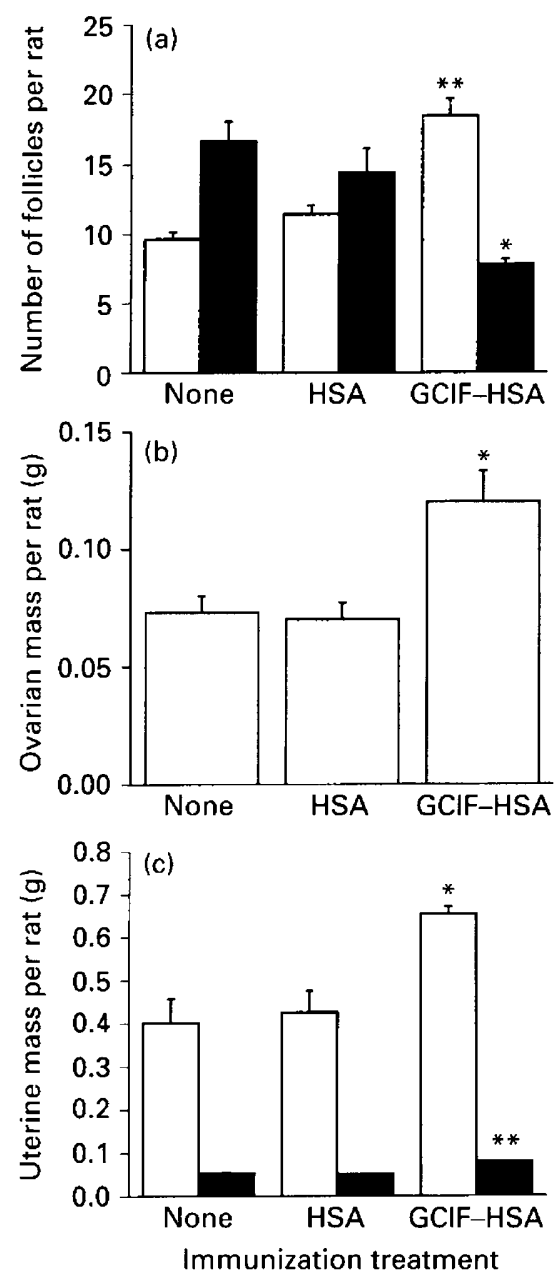

Fig. 1. Effects of immunization of female rats with human serum albumin (HSA) alone or granulosa cell inhibitory factor (GCIF)-HSA conjugate on (a) the numbers of large $(\square)$ and small $(\square)$ follicles per rat, (b) the ovarian mass, and (c) the wet $(\square)$ and dry ( $\square$ ) uterine masses. Values are means \pm SEM for five replicates per treatment. ${ }^{*} P<0.05 ;{ }^{* *} P<0.001$ : significantly different from both non-immunized controls.

injections but emulsified this time in NUFA. Over a period of two breeding seasons, a total of eight booster injections were given at intervals of 6-10 weeks after the primary immunization. Blood samples were taken before the primary injection and at regular intervals (on days 14, 42, 84 and 560 after boost 1) for measurement of antibody titre.

\section{Measurement of ovulation rate in sheep}

The oestrous cycles of all sheep were synchronized with a standard intra-vaginal progestogen sponge treatment (Gordon, 1983). The sponges $(60 \mathrm{mg}$ medroxyprogesterone acetate per sponge, J\&M Veterinary Services, Castleknock, Dublin) were inserted on the day of boost and removed 12 days later. Ewes were run with a vasectomized raddled ram from the day of sponge removal and checked daily from
24-72 $\mathrm{h}$ for raddle markings indicating that oestrus had occurred. Ovulation rate in all ewes was measured by midventral laparoscopy during the subsequent luteal phase (10-12 days after oestrus detection) of that cycle. All corpora lutea and the number of follicles $>3 \mathrm{~mm}$ in diameter present on both ovaries were counted.

\section{Measurement of antibody titres}

Blood samples from sheep were taken into glass vacutainers (Becton-Dickinson Systems Europe, Grenoble) and held at $37^{\circ} \mathrm{C}$ for $1 \mathrm{~h}$ and then at $4^{\circ} \mathrm{C}$ overnight. Serum was separated by centrifugation at $300 \mathrm{~g}$ for $30 \mathrm{~min}$ and stored at $-20^{\circ} \mathrm{C}$ until processing for antibody titre studies. Antibody titres were measured using a solid phase enzymeimmunoassay (Morris et al., 1993). Because the GCIF fraction is not a pure preparation, it was not possible to measure the antibody titres specifically raised against GCIF. However, antibody titres against GnRH were measured in all ewes as an index of the efficiency of the conjugation and immunization procedures with a small peptide.

\section{Granulosa cell culture}

Granulosa cells were collected from bovine follicles $<10$ $\mathrm{mm}$ in diameter and plated at a concentration of $2 \times 10^{5}$ cells $\mathrm{ml}^{-1}$ of MEM tissue culture medium with $10 \%$ fetal calf serum (FCS) in 12-well tissue culture plates as described by Hynes et al. (1996a). All granulosa cells were then pre-cultured for $24 \mathrm{~h}$ at $37^{\circ} \mathrm{C}$ in a $5 \% \mathrm{CO}_{2}$ atmosphere. After this initial $24 \mathrm{~h}$ culture period, the spent culture medium was removed and replaced by $1 \mathrm{ml}$ per well of fresh medium containing $0.1 \%$ FCS. GCIF was added at random to culture wells at concentrations of $0,0.1$ and $1 \mu \mathrm{g} \mathrm{ml}^{-1}$. Antisera from sheep immunized against HSA and GCIF were added to wells containing GCIF at three concentrations $\left(0.1,1\right.$ or $\left.10 \mu \mathrm{ml}^{-1}\right)$ at random; these additions of antiserum were in addition to the presence of $0.1 \%$ FCS. $\left[{ }^{3} \mathrm{H}\right]$ thymidine (methyl$\left[{ }^{3} \mathrm{H}\right]$ thymidine, Trk. $418,1 \mathrm{mCi} \mathrm{ml}^{-1}$, Amersham International plc, Amersham) was also added to all wells at the same time ( $2 \mu \mathrm{l}$ of a $1 \mathrm{mCi} \mathrm{ml}^{-1}$ solution). The granulosa cells were then re-incubated for a further $24 \mathrm{~h}$ after which they were harvested and cell proliferation was measured as described by Hynes et al. (1996a).

\section{Statistical analysis}

Data from the experiments on the effects of immunization of rats, and on the effects of antiserum from immunized sheep in reducing the inhibitory action of GCIF on granulosa cell proliferation in culture were analysed by analysis of variance followed by a post hoc Scheffe's $S$ test. Data on ovulation rates and the number of ovarian follicles from the experiments on the effects of immunization of sheep were analysed both by analysis of variance in a repeated measures design (after a square root transformation) and by the chisquared test. 

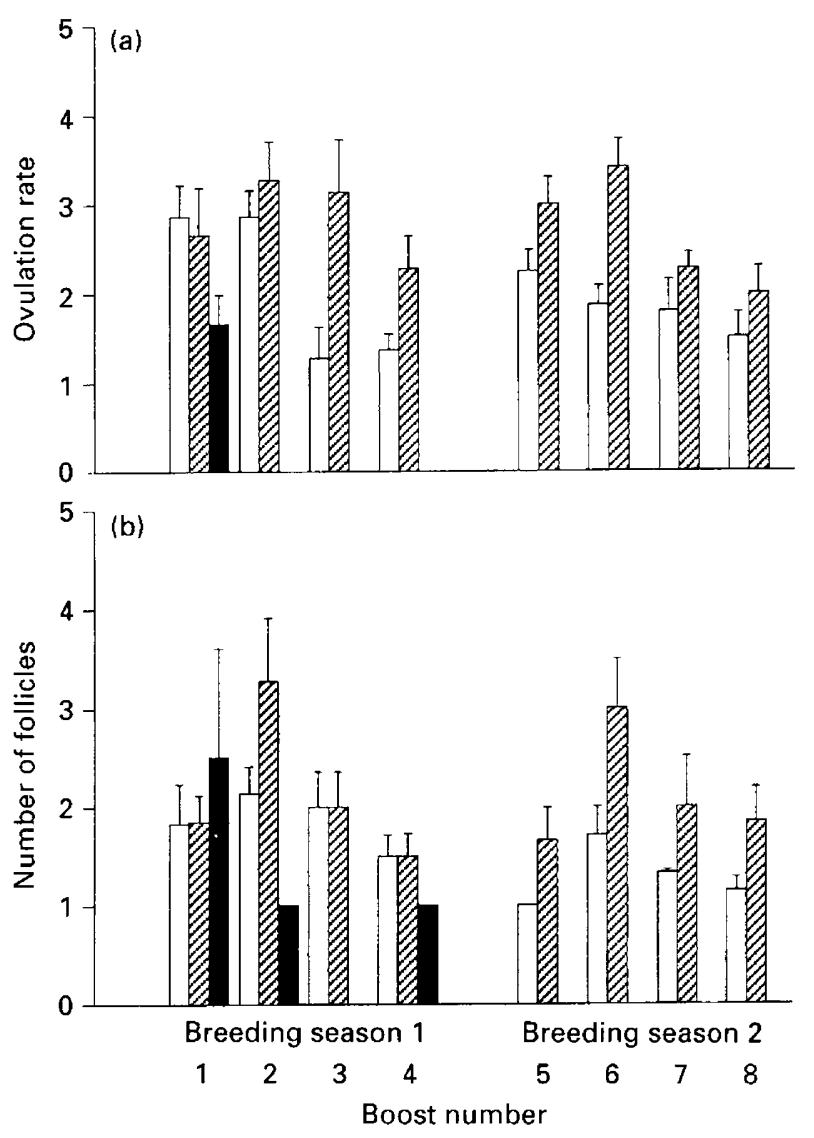

Fig. 2. Effects of immunization of female sheep with human serum albumin (HSA) alone $(\square)$, granulosa cell inhibitory factor GCIF(1)-HSA ( $\square$ ) or GnRH-HSA ( $\square$ ) over two breeding seasons on (a) ovulation rate and (b) number of follicles with a diameter $>3 \mathrm{~mm}$ per animal. Sheep immunized with GnRH-HSA were boosted only once. They did not ovulate after the first boost and had no follicles $>$ $3 \mathrm{~mm}$ diameter after the first breeding season. Values are means \pm SEM based on all animals (ovulators and non-ovulators) and involving 7-8 replicates. The overall ovulation rate for GCIFimmunized sheep was significantiy different from that of HSAimmunized sheep $(P<0.01)$. The number of follicles for GCIF- and HSA-immunized sheep were not significantly different $(P>0.05)$.

\section{Results}

\section{Effects of immunization against GCIF on rat follicular, ovarian and uterine growth and on liver and kidney masses}

Immunization of rats against the GCIF-HSA conjugate almost doubled $(P<0.001)$ the number of large follicles and, in contrast, approximately halved $(P<0.05)$ the number of small follicles as compared with the two control treatments (Fig. 1a). The total number of follicles was unchanged $(P>0.05)$ after GCIF immunization.

Mean ovarian mass in the GCIF-immunized rats was increased by about $70 \%$ (Fig. 1b; $P<0.05$ ) and uterine wet (Fig. 1c; $P<0.05)$ and dry $(P<0.001)$ masses were also increased markedly compared with controls.

Immunization against GCIF did not affect liver or kidney masses $(P>0.05$ ). Liver masses (mean $\pm \mathrm{SEM}, n=5$ per treatment) were $8.7 \pm 0.50$ (non-immunized controls), $9.1 \pm$ 0.34 (HSA-immunized) and $8.5 \pm 0.40 \mathrm{~g}$ (GCIF-immunized). Kidney masses were (mean $\pm \mathrm{SEM}, n=5$ per treatment) $1.52 \pm 0.08$ (non-immunized controls), $1.52 \pm 0.06$ (HSAimmunized) and $1.43 \pm 0.08 \mathrm{~g}$ (GCIF-immunized).

\section{Effect of immunization against GCIF and $\mathrm{GnRH}$ on ovulation rate and follicle number in sheep}

The effects of immunization against GCIF on ovulation rate and follicle numbers are shown (Fig. 2, Tables 1 and 2). With the exception of the first boost, ovulation rate over eight boosts was increased in the GCIF-immunized sheep (Fig. 2a, Table 1; $P<0.01$; overall mean of $2.75 \pm 0.15$ ovulations for the GCIF-immunized animals versus $1.85 \pm 0.12$ for the HSA-immunized animals). When only animals that had ovulated were included in the analysis, immunization against GCIF increased the average ovulation rate by $36 \%$ $(2.80 \pm 0.14$ versus $2.05 \pm 0.13)$. The maximum increase in ovulation rate $(140 \%)$ was recorded after boost 3 in GCIFimmunized animals. When all animals were included in the analysis, immunization against GCIF increased ovulation rate by an average of $48 \%$, with a maximum increase of $>180 \%$ after boost 3 .

A frequency distribution table for ovulation rate (Table 1) shows that $50 \%$ of the cycles of GCIF-immunized sheep resulted in three or more ovulations compared with only $21 \%$ of the cycles of HSA-immunized sheep. This increase in ovulation rate was the result of a greater number of sheep having three ovulations rather than a smaller number having very high ovulation rates.

The data from all cycles with one or more ovulations indicate that immunization against GCIF did not affect the number of cycles with ovulation on both sides. In 32 of 58 cycles (55\%) of ovulating sheep that were immunized against HSA, there were no ovulations on one side, in contrast to 27 of 55 cycles $(49 \%)$ of ovulating sheep that were immunized against GCIF $(P>0.05)$.

In contrast, the data from cycles with ovulations on one side only showed that immunization with GCIF increased the number of ovulations on that side. There were 15 of 32 cycles $(47 \%)$ with two or more ovulations on the ovulating ovary in sheep that were immunized against HSA, in contrast to 23 of 27 cycles $(85 \%)$ in sheep that were immunized against GCIF $(P<0.01)$.

The effects of immunization against GCIF on follicles were much less marked than the effects on ovulation. While the average number of follicles of $\geq 3 \mathrm{~mm}$ in diameter present on the ovaries was increased after immunization against GCIF (Fig. 2a, Table 2), this increase was neither consistent nor significant $(P>0.05)$.

Immunization against $\mathrm{GnRH}$ inhibited ovulation. In the first cycle after the first booster injection, only three sheep had ovulated. Although no further booster injections were given for the duration of the experiment, ovulation was abolished in all GnRH-immunized animals for the remainder of the experiment. The growth of follicles to more than $3 \mathrm{~mm}$ in diameter was also reduced after immunization against GnRH. All sheep immunized against GnRH attained Downloaded from Bioscientifica.com at 04/26/2023 02:37:25AM 
Table 1. The frequency distribution of the ovulation rate for human serum albumin (HSA)- and granulosa cell inhibitory factor (GCIF)-immunized ewes

\begin{tabular}{lcccccccc}
\hline & & \multicolumn{7}{c}{ Ovulation rate class $(\%)$} \\
\cline { 3 - 9 } Immunization treatment & Cycles & 0 & 1 & 2 & 3 & 4 & 5 & 6 \\
\hline HSA & 64 & $6(9)$ & $15(23)$ & $30(47)$ & $8(13)$ & $5(8)$ & - & - \\
GCIF-HSA & 56 & $1(2)$ & $4(7)$ & $23(41)$ & $15(27)$ & $9(16)$ & $3(5)$ & $1(2)$ \\
\hline
\end{tabular}

The HSA and GCIF-HSA immunization treatments were significantly different from each other (chi-squared test, $P<0.01$ ).

Table 2. The frequency distribution of the number of follicles $>3 \mathrm{~mm}$ in diameter for human serum albumin (HSA)- and granulosa cell inhibitory factor (GCIF)-immunized ewes

\begin{tabular}{lcccccccc}
\hline & & \multicolumn{7}{c}{ Number of follicles class (\%) } \\
\cline { 3 - 9 } Immunization treatment & Cycles & 0 & 1 & 2 & 3 & 4 & 5 & 6 \\
\hline HSA & 64 & $17(27)$ & $23(36)$ & $15(23)$ & $9(14)$ & - & - & - \\
GCIF-HSA & 56 & $10(18)$ & $15(27)$ & $20(35)$ & $7(12)$ & $2(4)$ & $1(2)$ & $1(2)$ \\
\hline
\end{tabular}

The HSA and GCIF-HSA immunization treatments were not significantly different (chi-squared test, $P>0.05$ ).

antibody titres $>1$ in 60000 by the end of the experiment ( 1 in $75500 \pm 6028$ over all measurements taken) and only two sheep at any stage had antibody titres $<1$ in 60000 . This result indicates that the peptide conjugation and immunization procedures used were efficient.

\section{Effects of serum from animals immunized against HSA and GCIF on the inhibition of cell proliferation induced by GCIF}

The inhibition exerted on granulosa cell proliferation by GCIF was approximately $40 \%$, and this result is consistent with previous results (Hynes et al., 1996a). Addition of serum collected from animals immunized against GCIF, at concentrations of $0.01 \%$ and $0.1 \%$, completely abolished the inhibitory effect of $0.1 \mu \mathrm{g}$ GCIF ml ${ }^{-1}$ and partially abolished the effect of $1 \mu \mathrm{g} \mathrm{ml}^{-1}$ (Fig. 3). A concentration of $1 \%$ of antiGCIF serum completely abolished the inhibitory activity of GCIF at all GCIF concentrations examined.

The addition of either FCS or serum from animals immunized against HSA did not affect the inhibitory activity of GCIF on granulosa cell proliferation in vitro (Fig. 3).

\section{Discussion}

Granulosa cell inhibitory factor (GCIF) is a novel and, as yet, uncharacterized factor present in the peak 4 fraction from a G-25 chromatographic separation of the low molecular weight fraction of bovine follicular fluid (Hynes et al., $1996 a, b)$. In the present study, active immunization of rats against GCIF resulted in an increase in ovarian and uterine masses and a concomitant increase in the number of large vesicular follicles present on the ovary. Immunization against GCIF also decreased the number of small follicles present on the ovary but did not affect the total number of follicles. These results are consistent with previous studies (Hynes et al., 1996a), in which direct administration of GCIF to cyclic female rats had opposite effects in that it decreased the number of large follicles per ovary while increasing the number of small follicles and also decreasing ovarian and uterine masses.

During the normal oestrous cycle of the rat, uterine mass reflects ovarian function and, particularly, oestradiol secretion. Increased uterine mass is associated with prooestrus and oestrous cycle stages during which numerous large follicles are present on the ovary, while lower uterine masses are associated with stages of the oestrous cycle during which large follicles are absent (Long and McLean Evans, 1922). This association between uterine mass and ovarian function has also been observed in animals immunized against either $\mathrm{LH}$ or $\mathrm{GnRH}$, which were found to have markedly decreased ovarian and uterine masses (Popkin and Fraser, 1985).

It would appear that GCIF is involved either in the selection of follicles to grow and reach pre-ovulatory status or in the maintenance of dominance by one follicle over others in the cohort. There are reports of the presence of a factor similar to GCIF in pig (Kigawa et al., 1986) and rat follicular fluid (Chakravorty et al., 1991, 1993).

In the present study, immunization of sheep against GCIF clearly increased ovulation rate. This increase was maintained as animals were boosted into the second year of the experiment. Because GCIF fraction is a relatively crude fraction, no effort was made to obtain antibody titres against the active factor in immunized animals.

If GCIF is a factor secreted by a dominant follicle or follicles to suppress the growth of other follicles, it is interesting to ask the question whether, in multiple ovulating animals such as sheep, it acts mainly to inhibit follicles on the same or the contralateral ovary. The finding that immunization against GCIF does not increase the number of 


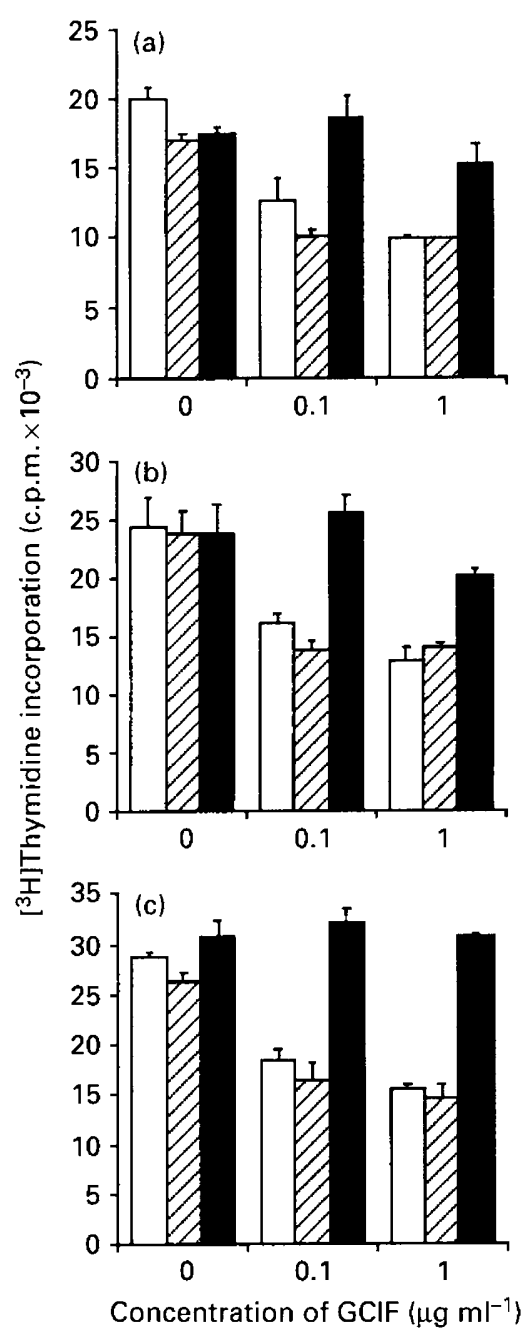

Fig. 3. The effects of different concentrations (a: $0.01 \%$; b: $0.1 \%$; and c: $1.0 \%$ ) of added sera and antisera (fetal calf serum (FCS), $\square$; antihuman serum albumin (anti-HSA), Z; anti-granulosa cell inhibitory factor (anti-GCIF), $\square$ ) on the inhibitory effect of GCIF on granulosa cell proliferation. Values are means \pm SEM for three replicates per treatment. In (a) with $0.01 \%$ added serum-antiserum, the anti-GCIF treatment was different from the FCS and the anti-HSA treatments in the presence of both $0.1(P<0.05)$ and $1.0 \mu \mathrm{g} \mathrm{GCIF} \mathrm{m}^{-1}(P<0.001)$. In (b) with $0.1 \%$ added serum-antiserum, the anti-GCIF was different from the FCS and the anti-HSA treatments in the presence of both 0.1 and $1.0 \mathrm{mg}$ GCIF $\mu \mathrm{l}^{-1}(P<0.01)$. In (c) with $1 \%$ added serum-antiserum, in the presence of 0.1 and $1.0 \mu \mathrm{g} \mathrm{GCIF} \mathrm{ml}{ }^{-1}$, the anti-GCIF was different from both the FCS and the anti-HSA treatments $(P<0.01)$.

sheep ovulating from both ovaries but does increase the number of ovulations on the single ovulating ovary indicates that GCIF is only active in the ovary in which it is produced and does not affect the contralateral ovary. This failure to affect the contralateral ovary in sheep may indicate that GCIF is restricted to the ovary that produces it but it is more likely that it is due to the fact that the concentration of GCIF is reduced greatly by dilution in the systemic blood system. It would be even more interesting to see if this failure to affect the contralateral ovary also occurs in mono-ovulating species, such as cattle. The results of the present study indicate clearly that the immunization effect on ovulation is not due to a nonspecific effect exerted on the secretion of hypothalamic or pituitary hormones but to a local ovarian effect.

There have been numerous studies in which sheep have been actively immunized against other follicular fluid factors, including the steroids, oestradiol, testosterone and androstenedione (Scaramuzzi and Hoskinson, 1984; Webb et al., 1984), and the peptides, oxytocin (Wathes et al., 1989) and inhibin (Morris et al., 1991; Murdoch, 1994). Immunization against each of these factors has been shown to alter ovulation rate in sheep, but all of these factors differ from GCIF either in molecular weight, solubility properties or action on ovarian cells.

Addition of anti-GCIF serum to granulosa cell cultures treated with GCIF abolished the inhibitory activity of the GCIF on granulosa cell proliferation, either completely or partially in almost all cases. This finding indicates that the serum of GCIF-immunized animals contained antibodies that blocked the inhibitory activity of GCIF on granulosa cell proliferation, as well as antibodies that increased large follicle growth and ovulation rate, presumably by binding some factor that inhibits follicular growth and ovulation. These data are consistent with the hypothesis that GCIF, which inhibits granulosa cell proliferation in vitro, also inhibits large follicle growth in vivo.

This study provides further evidence that a low molecular weight factor in follicular fluid, GCIF, which inhibits granulosa cell proliferation in vitro, inhibits large follicle growth and ovulation in vivo. This study also indicates that it may be possible to control ovulation rate by immunization against this factor.

The authors thank S. Hanrahan for the ovulation rate measurements, D. G. Morris for help with the immunization protocol and $P$. Joyce for technical assistance.

\section{References}

Briand JP, Muller S and Van Regenmortel MHV (1985) Synthetic peptides as antigens: pitfalls of conjugation methods Journal of Immunological Methods 78 $59-69$

Cahill JP, Driancourt MA and Findlay JK (1984) An inhibitory action at the ovarian level of ovine follicular fluid on PMSG-induced folliculogenesis in hypophysectomized ewes. In Proceedings of the 5th Ovarian Workshop, Illinois pp 35-39 Eds DO Toft and RJ Ryan. Plenum Press, New York

Chakravorty A, Mahesh VB and Mills TM (1991) Inhibition by diethylstilboestrol of proliferative potential of follicles of different sizes in immature rat ovaries Journal of Reproduction and Fertility 92 323-332.

Chakravorty A, Mahesh VB and Mills TM (1993) Control of peptides regulating mitosis of granulosa cells in immature rat ovary by oestrogen and gonadotrophin Journal of Reproduction and Fertility 97 91-100

Ginther OJ, Wiltbank MC, Fricke PM, Gibbons JR and Kot K (1996) Selection of the dominant follicle in cattle Biology of Reproduction $\mathbf{5 5}$ $1187-1194$

Goodfriend TL, Levine L and Fasman GD (1964) Antibodies to bradykinin and angiotensin: a use of carbodiimides in immunology Science 144 1344-1346

Gordon I (1983) Artificial control of oestrus and ovulation. In Controlled Breeding in Farm Animals pp 181-195 Ed. I Gordon. Pergamon Press, Oxford

Hynes AC, Kane MT and Sreenan JM (1996a) Partial purification from bovine follicular fluid of a factor of low molecular mass with inhibitory effects on 
the proliferation of bovine granulosa cells in vitro and on rat follicular development in vivo. Journal of Reproduction and Fertility 108 185-191

Hynes AC, Sreenan JM and Kane MT (1996b) Modulation of the effects of FSH, androstenedione, epidermal growth factor (EGF) and insulin-like growth factor I (IGF-I) on bovine granulosa cells by GCIF, a growthinhibitory factor of low molecular mass from bovine follicular fluid Journal of Reproduction and Fertility 108 193-197

Johnstone A and Thorpe R (1982) Immunochemistry in Practice Blackwell Scientific Publications, Oxford

Kigawa T, Ogawa T, Miyamura K and Iino Y (1986) Inhibitory activity of a low molecular weight substance extracted from porcine small follicular fluid on estradiol and progesterone secretions by rat granulosa cells in vitro and by rat ovaries in vivo. Endocrinologia Japonica 33 597-604

Long JA and McLean Evans H (1922) The oestrous cycle in the rat and its associated phenomena Memoirs of the University of California 6 1-138

McNatty KP and Sawers RS (1975) Relationship between the endocrine environment within the Graafian follicle and the subsequent rate of progesterone secretion by human granulosa cells in vitro. Journal of Endocrinology 66 391-400

Morris DG, McDermott MG and Sreenan JM (1991) Effect of immunizing prepubertal lambs of low and high ovulation rate genotypes with inhibin partially purified from bovine follicular fluid Theriogenology 35 339-350

Morris DG, McDermott MG, Diskin MG, Morrison CA, Swift PJ and
Sreenan JM (1993) Effect of immunization against synthetic peptide sequences of bovine inhibin $\alpha$-subunit on ovulation rate and twin-calving rate in heifers Journal of Reproduction and Fertility 97 255-261

Murdoch WJ (1994) Immunoregulation of mammalian fertility Life Sciences 55 1871-1886

Popkin RM and Fraser HM (1985) Changes in pituitary and ovarian LHRH receptors after active immunization of female rats against LH or LHRH Journal of Reproduction and Fertility 73 491-496

Scaramuzzi RJ and Hoskinson RM (1984) Active immunization against steroid hormones in the female. In Immunological Aspects of Reproduction in Mammals pp 445-474 Ed. DB Crighton. Butterworths, London

Spicer LJ and Echternkamp SE (1986) Ovarian follicular growth, function and turnover in cattle: a review Journal of Animal Science 62 428-451

Staros JV, Wright RW and Swingle DM (1986) Enhancement by $N$ hydroxysulfosuccinimide of water soluble carbodiimide-mediated coupling reactions Analytical Biochemistry 156 220-222

Wathes DC, Ayad VJ, McGoff SA and Morgan KL (1989) Effect of active immunization against oxytocin on gonadotrophin secretion and the establishment of pregnancy in the ewe Journal of Reproduction and Fertility 86 653-664

Webb R, Land RB and Pathiraja N (1984) Passive immunization against steroid hormones in the female. In Immunological Aspects of Reproduction in Mammals pp 475-499 Ed. DB Crighton. Butterworths, London 